This is the final peer-reviewed accepted manuscript of

FUNARI, VALERIO; BRAGA, ROBERTO; Syed Nadeem Hussain Bokhari; DINELLI, ENRICO; Thomas Meisel:

Solid residues from Italian municipal solid waste incinerators: A source for "critical" raw materials. WASTE

MANAGEMENT, 45. ISSN: 0956-053X

DOI: 10.1016/j.wasman.2014.11.005

The final published version is available online at:

http://dx.doi.org/10.1016/i.wasman.2014.11.005

Rights / License:

The terms and conditions for the reuse of this version of the manuscript are specified in the publishing policy. For all terms of use and more information see the publisher's website.

This item was downloaded from IRIS Università di Bologna (https://cris.unibo.it/)

When citing, please refer to the published version. 


\title{
Solid residues from Italian municipal solid waste incinerators: A source for "critical" raw materials
}

\author{
Valerio Funari $^{\mathrm{a}, *}$, Roberto Braga ${ }^{\mathrm{a}}$, Syed Nadeem Hussain Bokhari ${ }^{\mathrm{b}}$, Enrico Dinelli ${ }^{\mathrm{a}}$, Thomas Meisel ${ }^{\mathrm{b}}$ \\ a Dipartimento di Scienze Biologiche, Geologiche e Ambientali - Geology Division, University of Bologna, Piazza di Porta San Donato 1, 40126 Bologna, Italy \\ ${ }^{\mathrm{b}}$ General and Analytical Chemistry - Montanuniversität Leoben, Franz-Josef-Str. 18, 8700 Leoben, Austria
}

A R T I C L E I N F O

Keywords:

MSWI residues

Critical element

Gravitational partitioning

Substance flow analysis

\begin{abstract}
A B S T R A C T
The incineration of municipal solid wastes is an important part of the waste management system along with recycling and waste disposal, and the solid residues produced after the thermal process have received attention for environmental concerns and the recovery of valuable metals. This study focuses on the Critical Raw Materials (CRM) content in solid residues from two Italian municipal waste incinerator (MSWI) plants. We sampled untreated bottom ash and fly ash residues, i.e. the two main outputs of common grate furnace incinerators, and determined their total elemental composition with sensitive analytical techniques such as XRF and ICP MS. After the removal of a few coarse metallic objects from bottom ashes, the corresponding ICP solutions were obtained using strong digestion methods, to ensure the dissolution of the most refractory components that could host significant amounts of precious metals and CRM. The integration of accurate chemical data with a substance flow analysis, which takes into account the mass balance and uncertainties assessment, indicates that bottom and fly ashes can be considered as a low concentration stream of precious and high tech metals. The magnesium, copper, antimony and zinc contents are close to the corresponding values of a low grade ore. The distribution of the elements flow between bottom and fly ash, and within different grain size fractions of bottom ash, is appraised. Most elements are enriched in the bottom ash flow, especially in the fine grained fractions. However, the calculated transfer coefficients indicate that $\mathrm{Sb}$ and $\mathrm{Zn}$ strongly partition into the fly ashes. The comparison with available studies indicates that the CRM concentrations in the untreated solid residues are comparable with those residues that undergo post treatment beneficiations, e.g. separation between ferrous and non ferrous fractions. The suggested separate collection of "fresh" bottom ash, which could be processed for further mineral upgrading, can constitute an attractive option of the waste management system, when physical mechanical devices are not available or could not be implemented in old MSWI systems. The suggested procedure may lead to the improvement of recovery efficiency up to $83 \%$ for CRM and $94 \%$ for other valuable metals.
\end{abstract}

\section{Introduction}

The European waste policy discourages waste landfill in favor of waste recycling, recovery and, finally, waste to energy processes (EC, 2008). Today, the waste incineration represents the main stream method for the management of unsorted urban and industrial wastes in many industrialized countries. An integrated system of municipal solid waste incinerator (MSWI) reduces the volume of collected waste, destroys many toxic components and provides a source of alternative energy. Final solid residues are around 30\%of the total mass input and their reuse, as additive for construction

\footnotetext{
* Corresponding author. Tel.: +39 0512094959 (O), +39 3896835032 (mobile). E-mail address: valerio.funari@unibo.it (V. Funari).
}

materials (e.g.: Bertolini et al., 2004; Izquierdo et al., 2001), or their disposal in landfills invariably requires the assessment of the amount of hazardous elements, which can endanger the environment and the human health (e.g.: Li et al., 2004; Pan et al., 2013). Efforts have been made to characterise the chemical and mineralogical composition of the residues, including the leachable fractions (e.g.: Hu et al., 2012; Pan et al., 2013; Zhang et al., 2008b).

The growing body of chemical (and mineralogical) data is adding a new perspective on solid waste as a secondary source of metals and other valuable chemical elements. During the last few years, several authors investigated on precious metals (mostly Ag, $\mathrm{Au}, \mathrm{Pt}$ ) in MSWI residues (Jung and Osako, 2009a; Muchova et al., 2009). Recently, the European Commission $(2010,2014)$ defined a list of "critical" raw materials on the basis of their rela 
tive economic importance and supply risk. Critical Raw Materials (CRM) are chemical elements and minerals such as $\mathrm{Be}, \mathrm{Co}, \mathrm{Cr}, \mathrm{Ga}$, $\mathrm{Ge}$, In, Mg, Nb, Sb, W, Platinum Group Elements (PGEs), Rare Earth Elements (REE), borates, coking coal, fluorspar, graphite, magnesite, phosphate rock, silicon metal, which are important for the technological development. In this regard, recent works reported the total content of CRM in solid residues from incineration plants (Hasegawa et al., 2014), also inspecting the annual flow for several elements (Morf et al., 2013; Allegrini et al., 2014).

Although several studies dealt with the fractionation of potentially harmful elements in different grain size fractions of bottom and fly ashes (De Boom and Degrez, 2012; Yao et al., 2013; Zhang et al., 2008a), the distribution of CRM in such fractions has not been fully explored. Morf et al. (2013) and Allegrini et al.(2014) investigated the CRM content in treated bottom ashes (i.e., after magnetic separation or with automatic samplers of the MSWI system) and in grain size fraction of the treated residues (i.e., non ferrous batches). However, the treatment after quenching of bottom ash (e.g. separation between magnetic and diamagnetic materials) might not be a common practice at the facility scale, especially when a 1015 years old system is operating.

For this reason we focus on the characterisation and the CRM potential evaluation of the main outputs of common incineration systems: (1) the whole and "fresh" (=after quenching) bottom ash residues and (2) the untreated (=prior to any filtration) fly ashes. We provide the elements mass fraction by XRF and ICP MS and the estimated element flows $(\mathrm{kg} / \mathrm{a})$ of some CRM and other valuable metals through a substance flow analysis, as carried out in other works (Astrup et al., 2011; Belevi and Moench, 2000; Brunner and Ernst, 1986; Brunner and Mönch, 1986; Morf et al., 2013; Zhang et al., 2008a). In general, the annual flow evaluation lack in balanced mass account and in a clear description of uncertainty assessment (Astrup et al., 2015), but in this contribution we provide the necessary information for the substance flow calculation to prove its integrity and to facilitate the inter comparison with existing works.

Applying the same methods of analysis and elements flow evaluation, we further explore the different grain sizes of "fresh" bottom ash stocks by means of a visual aided separation, easy for unskilled operators, in order to understand if the recovery potential of bottom ashes can be improved immediately after the incineration process and with low costs for the plant managers. In addition, the separate collection of fresh untreated bottom ash may constitute a good choice when physical mechanical devices are not available or could not be implemented in old MSWI systems.

The CRM elements Be, $\mathrm{Co}, \mathrm{Cr}, \mathrm{Ga}, \mathrm{Mg}, \mathrm{Nb}, \mathrm{Sb}, \mathrm{REE}, \mathrm{W}$ and $\mathrm{Y}$ are investigated in this study and hereafter called CRM for simplicity reason.

\section{Materials and method}

\subsection{Bottom and fly ash samples}

We collected the final solid residues from two waste incinerator plants from Northern Italy, named SWI 1 and SWI 2. The selected incinerators have similar thermo recycling technology, with two boiler systems that produce an average electricity of $85,000 \mathrm{MW} / \mathrm{h}$ per year. The incineration systems consist of two lines that drive the collected waste, about $0.13 \mathrm{Mt} / \mathrm{a}$ (this value refers to the mean of the two plants), in the furnace that operates at temperatures between 850 and $1100{ }^{\circ} \mathrm{C}$. More than $90 \%$ of the solid waste input is made of unsorted municipal solid waste while the remaining consists of special waste derived from pre processing of the for mer. Moreover, the input to the SWI 1 also includes pharmaceuti cal/ hospital waste.
The main outputs of the incineration process are slag, bottom and fly ashes. Hot slag and bottom ashes (hereafter called BA) are quenched in cooling tanks. The residence time of the residue in the water varies between 4 and $8 \mathrm{~h}$ depending on the through put of waste and on its calorific value. At this stage, a broad magnetic separation removes the coarse ferric scrap; since this residue is completely recycled, it is not considered in our investigation. Belt conveyors transport the remaining wet residues (depurated only by the largest ferric objects, which is not considered in the final mass weighted for the calculation of elements flow) to a tem porary outdoor storage site where the BA are piled up. There is no further post combustion treatment (e.g., trammel screening, mag netic separation). The total annual output of BA is about $0.023 \mathrm{Mt} / \mathrm{a}$ and $0.032 \mathrm{Mt} / \mathrm{a}$ for SWI 1 and SWI 2, respectively.

Untreated fly ashes from the furnace (hereafter, FA) are among the first residues produced during the incineration in both plants. These residues derive from mechanical waggle of the FA evacuation systems and are separately collected in big bags. Such kind of ash is typical of many conventional MSWI systems. Fly ashes undergo further steps of physical and chemical treatment (ESP, scrubber and bag filter with chemical additives) but these treated fly ashes are not the object of the present work. The total annual output of FA is about 2400 t/a and 3200 t/a for SWI 1 and SWI 2, respectively.

The overall process ensures that there is no mixing between FA and BA.

\subsection{Sampling and sample preparation}

The BA sampling from the two plants (SWI 1 and SWI 2) was carried out in a typical day of the process activity in May 2013, directly from the outdoor storage site. Each sampled stockpile was 34 meters high and representative of two month deposition in total, since the last loading took place in early March 2013.

The samples collection followed the "stratified simple random sampling", a method outlined in the Italian technical standard UNI 10802 (2013). The method is suitable in case of solid waste forming an accumulation, which contains separate units or "strata" with vertical or horizontal direction. The strata should be readily distinguishable by specific features (e.g., colour, grain size, etc.) and are followed by drawing a simple random sample from each stratum. Generally, the stratified simple random sampling is more representative of the population than the simple random sampling (Kaur et al., 1996 and reference therein).

As the hill shaped pile was clearly influenced by gravitational sorting, the variable that allows to stratify the BA stockpile is the gravity, which affects the grain size distribution of the solid material. Although the high deposition rate of materials, a visual inspection of the BA pile revealed coarser BA at the bottom of the pile and fine grained BA at the top. This visual inspection allowed us to identify three layers (strata) based on their prevalent grain size. Layers are named B, M, T respectively for bottom, intermediate and top. The influence of the gravity in grain size sorting is appraised by a granulometric analysis on primary samples con ducted for the two plants (Fig. 1). Directly from fresh BA stock, $78 \mathrm{~kg}$ primary sample was taken from each layer. Each batch was split in four portions, the opposite portions were mixed together and again split for three times, to ensure homogeneity and representativeness. Three subsamples were taken from pri mary samples (i.e. each layer), nine in total from each incinerator plant. BA have $510 \mathrm{wt} \%$ moisture content and show $\mathrm{cm}$ sized fragments of metals, glassware and ceramics. All samples were oven dried at $40{ }^{\circ} \mathrm{C}$ for one week under continuous air flow.

FA were collected in December 2013 from "big bags" with a random sampling method (UNI 10802, 2013). In both incinerator plants, about $5 \mathrm{~kg}$ FA primary sample was collected from almost 

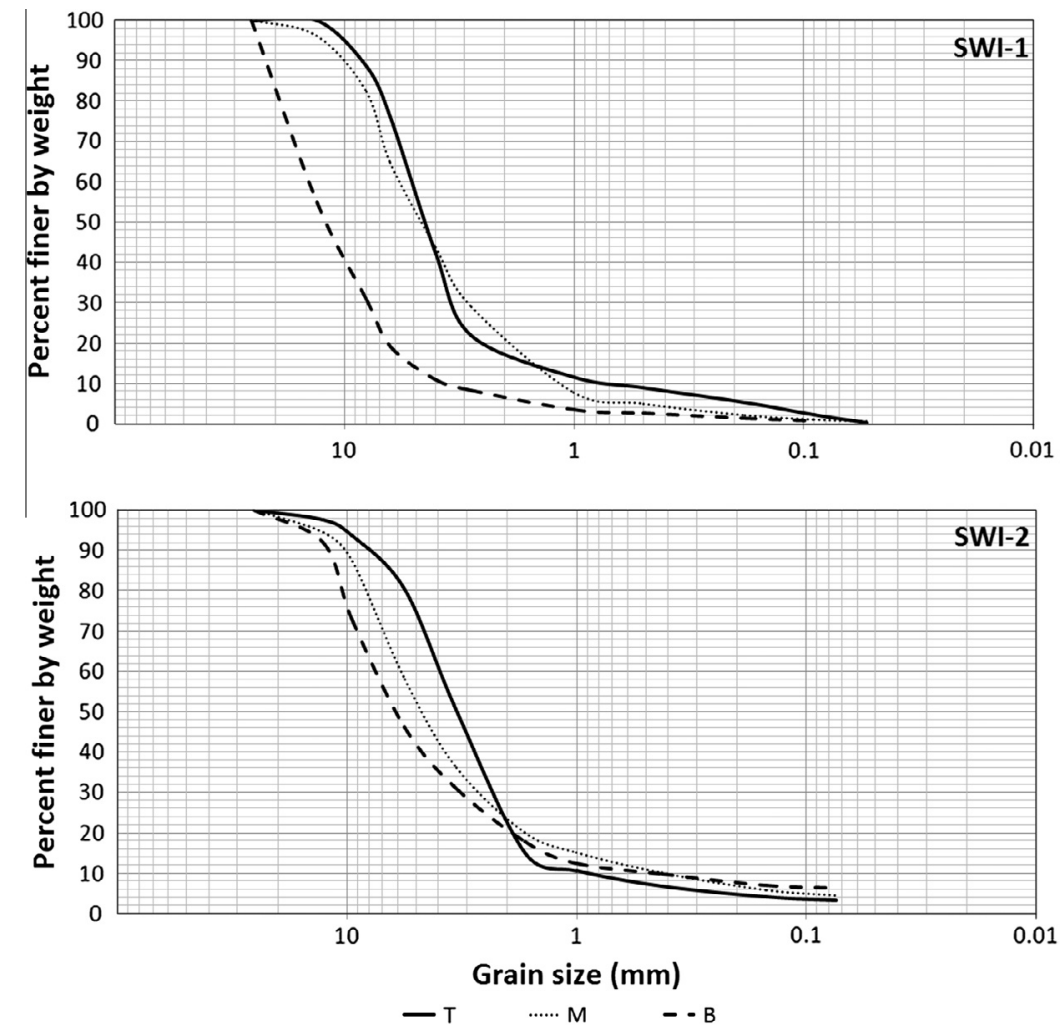

Fig. 1. Granulometric analysis of the sampled material in B, M and T layers, for SWI-1 and SWI-2.

full big bags and blended from a large number of increments in order to reach representativeness. FA samples are very fine grained with very low moisture content, i.e. $<1 \mathrm{wt} . \%$. They were oven dried at $40^{\circ} \mathrm{C}$ overnight.

For our study we did not average samples taken over a longer period. Although BA were collected about seven months earlier than FA, the latter were collected before the system cleaning and we assumed it is comparable to BA because of the low output flow rate of FA. The equipment of the selected MSWI plants did not allow to collect FA residues corresponding to the same BA mass burning.

The chosen samples of BA and FA were homogenized with an agate vibratory disk mill for $30 \mathrm{~min}$ and milled again with an agate mortar until the whole material had size $<40 \mu \mathrm{m}$ within one week after sampling. Only a few coarse metallic objects $(>1 \mathrm{~cm})$, which could not be size reduced, were removed from BA samples in order to pulverise the "fresh" BA materials, including the subcentimetric fragments of metal.

\subsection{Analytical techniques}

The bulk chemical composition of milled material was obtained by $\mathrm{X}$ ray fluorescence spectrometry (XRF) and inductively coupled plasma mass spectrometry (ICP MS) techniques.

\subsection{1. $X$ ray fluorescence spectrometry}

Major (>1 g/100 g), minor (0.1 1.0 g/100 g) and trace (<0.1 g/ $100 \mathrm{~g})$ element analyses were performed on the bulk sample of each layer (B, M, T) for the two selected MSWI plants. The total number of analysed samples is 18 , three samples for each layer. The total elemental chemistry was determined on thin layer pressed powder pellet $(\phi 37 \mathrm{~mm})$ in boric acid binder, using three grams of the dried and milled sample. A sequential wavelength dis- persive $X$ ray fluorescence (XRF) spectrometer (Axios Panalytical), equipped with a $4 \mathrm{~kW}$ Rh tube and SuperQ 3.0 software, was used at the Department of Biological Geological and Environmental Sciences Geology Division of the University of Bologna. The estimated precision for major and trace element determinations are better than $5 \%$ except for those elements $\leqslant 10 \mathrm{mg} / \mathrm{kg}$ (10 15\%). Total loss on ignition (LOI) was gravimetrically estimated after overnight heating at $950{ }^{\circ} \mathrm{C}$. The following elements were analysed by XRF: $\mathrm{Si}$, Ti, Al, Fe, Mn, Mg, Ca, Na, K, P, As, Ba, Ce, Co, Cr, Cu, Ga, La, Mo, Nb, Nd, Ni, Pb, Rb, Sc, Sm, Sn, Sr, V, Y, Zn and Zr.

\subsubsection{Inductively coupled plasma spectrometry}

Inductively coupled plasma mass spectrometry (ICP MS) was used for the determination of the total elemental composition of FA samples (from both MSWI plants; 2 samples each) and BA samples (from SWI 1 layers; 3 samples each, 9 in total).

For BA analyses, $0.2 \mathrm{~g}$ dried and milled sample were totally digested with high purity grade $\mathrm{HNO}_{3}, \mathrm{HClO}_{4}$ and $\mathrm{HF}$ (Merck, Darmstadt, Germany) on a hot plate at $170{ }^{\circ} \mathrm{C}$ until the digested solution was clear. Final $\mathrm{H}_{2} \mathrm{O}_{2}$ treatment followed the digestion procedure to dissolve the carbonic refractory fraction. Dissolved samples were dried out and then diluted to the mark in ultrapure water obtained from a Milli Q purifier system (Millipore Corp., Bedford, MA, USA). The analyses were carried out using an X Series Thermo Scientific spectrometer at the Department of Physics and Earth Sciences of the University of Ferrara. Specific amounts of $\mathrm{Rh}, \mathrm{Re}$ and In were added to the analysed solutions as an internal standard, in order to correct for instrument drift. The precision, based on replicated analyses of samples and standards, is estimated as better than $10 \%$ for all elements well above the detection limit.

FA samples were analysed at the department of General and Analytical Chemistry of Montanuniversität Leoben using the $\mathrm{Na}_{2} \mathrm{O}_{2}$ sintering technique (Meisel et al., 2002) as a method of total digestion. For the digestion $0.1000 \mathrm{~g}$ of dried and milled samples were weighed into glassy carbon crucibles and each of them were mixed thoroughly with about $0.6 \mathrm{~g}$ of fine powered $\mathrm{Na}_{2} \mathrm{O}_{2}$ by a glass stirrer. The carbon crucibles were sintered in a muffle furnace at 
Table 1

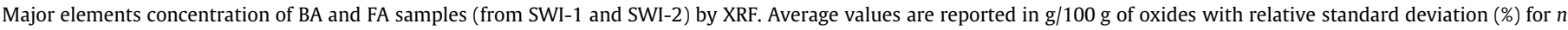
number of samples. Loss of ignition (L.O.I.) value is also provided.

\begin{tabular}{|c|c|c|c|c|}
\hline \multirow[t]{2}{*}{ Element } & \multicolumn{2}{|l|}{ BA } & \multicolumn{2}{|l|}{ FA } \\
\hline & SWI-1 $(n=9)(\%)$ & SWI-2 $(n=9)(\%)$ & SWI-1 $(n=9)(\%)$ & SWI-2 $(n=9)(\%)$ \\
\hline $\mathrm{SiO}_{2}$ & $33.0 \pm 20$ & $27.9 \pm 23$ & $9.66 \pm 1$ & $13.5 \pm 2$ \\
\hline $\mathrm{TiO}_{2}$ & $1.22 \pm 13$ & $1.29 \pm 17$ & $1.52 \pm 11$ & $2.10 \pm 7$ \\
\hline $\mathrm{Al}_{2} \mathrm{O}_{3}$ & $8.99 \pm 14$ & $7.58 \pm 9$ & $3.32 \pm 17$ & $6.32 \pm 18$ \\
\hline $\mathrm{Fe} 2 \mathrm{O} 3$ & $9.92 \pm 20$ & $10.3 \pm 39$ & $2.94 \pm 79$ & $2.51 \pm 54$ \\
\hline $\mathrm{MnO}$ & $0.15 \pm 22$ & $0.13 \pm 18$ & $0.13 \pm 49$ & $0.12 \pm 29$ \\
\hline $\mathrm{MgO}$ & $7.23 \pm 76$ & $2.89 \pm 8$ & $7.15 \pm 46$ & $2.72 \pm 58$ \\
\hline $\mathrm{CaO}$ & $23.4 \pm 21$ & $33.3 \pm 17$ & $38.6 \pm 11$ & $42.2 \pm 4$ \\
\hline $\mathrm{Na}_{2} \mathrm{O}$ & $3.11 \pm 14$ & $2.52 \pm 32$ & $6.89 \pm 2$ & $8.61 \pm 8$ \\
\hline $\mathrm{K}_{2} \mathrm{O}$ & $1.48 \pm 16$ & $1.09 \pm 9$ & $4.24 \pm 11$ & $5.23 \pm 10$ \\
\hline $\mathrm{P}_{2} \mathrm{O}_{5}$ & $2.18 \pm 15$ & $1.12 \pm 20$ & $1.08 \pm 38$ & $1.55 \pm 34$ \\
\hline L.O.I. & $9.30 \pm 39$ & $11.9 \pm 41$ & $24.5 \pm 15$ & $15.2 \pm 13$ \\
\hline
\end{tabular}

$480{ }^{\circ} \mathrm{C}$ for $30 \mathrm{~min}$, then they were allowed to cool down to room temperature. After cooling, crucibles were kept in Teflon beakers. Milli Q water was added drop wise in the crucibles till the reaction ceased. The Teflon beakers were heated again $\left(90^{\circ} \mathrm{C}\right)$ along with magnetic stirrer stirring at $250 \mathrm{rpm}$ for $30 \mathrm{~min}$. The final solution was centrifuged at $4000 \mathrm{rpm}$ for $5 \mathrm{~min}$. The clear solution from centrifugation tubes was poured into a $100 \mathrm{ml}$ volumetric flask, while 2 $\mathrm{ml}$ of concentrated $\mathrm{HCl}$ (reagent grade) and $3 \mathrm{ml}$ of $3 \mathrm{~mol} / \mathrm{l} \mathrm{HCl}$ were added to the crucibles and the residues obtained after centrifugation, respectively, to dissolve the precipitates. All the solutions were poured from centrifuging tubes, Teflon beakers and crucibles into the respective labeled flasks and diluted to the mark (up to 100 $\mathrm{ml}$ ). One $\mathrm{ml}$ of the final solution was taken for ICP MS measure ment and further diluted up to $5 \mathrm{ml}$ total with $1 \%$ of $\mathrm{HNO}_{3}$. $100 \mu \mathrm{l}$ of $\mathrm{In} /$ $\operatorname{Re}(100 \mathrm{ppb})$ and $50 \mu \mathrm{l}$ of $\mathrm{Ge}(1 \mathrm{ppm})$ were added as internal standard. Blank solution and reference materials were also treated similarly before final measurements with ICP MS.

\subsection{Substance flow analysis}

An estimation of substance flow (Brunner and Rechberger, 2004) for SWI 1 BA and FA was carried out on single output products and their grain size fractions. The substance flow analysis allows to determine the annual flow of commodities within output products and the transfer coefficient from inputs to outputs. The spatial system boundary for the experiment was the MSWI process itself, from the waste collection to output products, and included the sampling and the preliminary samples clustering in grain size fractions. The temporal system boundary was defined as one year, assuming that the sampled material is representative for one year process activity (i.e., 2013).

For the calculation of total annual flow for BA and FA we used following simple equations:

$F_{\mathrm{BA}} \quad C_{i} \cdot O_{\mathrm{BA}}$

$F_{\mathrm{FA}} \quad C_{i} \cdot O_{\mathrm{FA}}$

where $F$ is the annual flow in mass/time, $C_{i}$ is the measured concen tration of element $i$ in mass/mass and $O$ is the total output mass/ time for the BA and FA.

The evaluation of the uncertainty propagation follows the Gauss' law of error propagation. Since only coarser fractions show strongly deviating data and skewed distribution, we decided to calculate means and error propagation assuming normal distribution.

Table 2

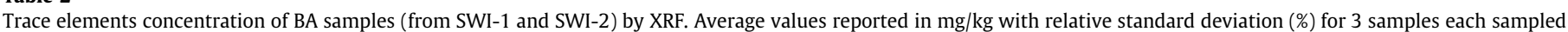
layer.

\begin{tabular}{|c|c|c|c|c|c|c|}
\hline \multirow[t]{2}{*}{ Element } & \multicolumn{3}{|c|}{ Sampled layers of BA (SWI-1) } & \multicolumn{3}{|c|}{ Sampled layers of BA (SWI-2) } \\
\hline & B (\%) & $\mathrm{M}(\%)$ & $\mathrm{T}(\%)$ & $\mathrm{B}(\%)$ & $\mathrm{M}(\%)$ & $\mathrm{T}(\%)$ \\
\hline As & $9.4 \pm 67$ & $4.2 \pm 24$ & $6.2 \pm 25$ & $3.3 \pm 17$ & $2.9 \pm 10$ & $11.0 \pm 24$ \\
\hline $\mathrm{Ba}$ & $1122 \pm 14$ & $1110 \pm 22$ & $1042 \pm 16$ & $666 \pm 17$ & $1232 \pm 65$ & $583 \pm 4$ \\
\hline $\mathrm{Ce}$ & $23.7 \pm 51$ & $25.8 \pm 49$ & $35.6 \pm 38$ & $19.7 \pm 11$ & $32.3 \pm 57$ & $30.1 \pm 13$ \\
\hline Co & $22.7 \pm 61$ & $26.6 \pm 16$ & $24.7 \pm 20$ & $25.7 \pm 66$ & $25.3 \pm 45$ & $31.0 \pm 14$ \\
\hline $\mathrm{Cr}$ & $606 \pm 31$ & $590 \pm 16$ & $426 \pm 34$ & $568 \pm 11$ & $695 \pm 14$ & $640 \pm 12$ \\
\hline $\mathrm{Cu}$ & $2459 \pm 30$ & $2549 \pm 29$ & $2452 \pm 30$ & $3068 \pm 91$ & $1907 \pm 55$ & $2599 \pm 27$ \\
\hline $\mathrm{Ga}$ & $9.4 \pm 25$ & $9.7 \pm 38$ & $9.0 \pm 35$ & $6.7 \pm 35$ & $6.7 \pm 9$ & $14.3 \pm 12$ \\
\hline La & $14.1 \pm 42$ & $16.5 \pm 36$ & $17.1 \pm 33$ & $6.3 \pm 18$ & $8.3 \pm 45$ & $12.7 \pm 30$ \\
\hline Mo & $15.2 \pm 29$ & $20.0 \pm 12$ & $20.6 \pm 25$ & $8.7 \pm 13$ & $8.7 \pm 18$ & $10.1 \pm 34$ \\
\hline $\mathrm{Nb}$ & $12.4 \pm 31$ & $15.8 \pm 34$ & $16.3 \pm 27$ & $6.7 \pm 9$ & $6.0 \pm 33$ & $12.6 \pm 8$ \\
\hline $\mathrm{Nd}$ & $8.7 \pm 37$ & $9.8 \pm 24$ & $11.2 \pm 36$ & $8.3 \pm 7$ & $10.0 \pm 30$ & $22.8 \pm 9$ \\
\hline $\mathrm{Ni}$ & $163 \pm 28$ & $184 \pm 17$ & $233 \pm 23$ & $98.3 \pm 23$ & $103 \pm 36$ & $139 \pm 12$ \\
\hline $\mathrm{Pb}$ & $354 \pm 30$ & $611 \pm 13$ & $452 \pm 23$ & $543 \pm 46$ & $820 \pm 17$ & $1026 \pm 39$ \\
\hline $\mathrm{Rb}$ & $25.5 \pm 20$ & $33.0 \pm 15$ & $32.0 \pm 17$ & $22.3 \pm 3$ & $19.7 \pm 13$ & $44.3 \pm 17$ \\
\hline Sc & $14.3 \pm 17$ & $8.8 \pm 8$ & $13.5 \pm 4$ & $9.1 \pm 11$ & $7.5 \pm 9$ & $9.7 \pm 4$ \\
\hline $\mathrm{Sm}$ & $1.8 \pm 6$ & $1.6 \pm 4$ & $2.5 \pm 5$ & $1.5 \pm 47$ & $2.0 \pm 1$ & $7.0 \pm 11$ \\
\hline Sn & $358 \pm 81$ & $157 \pm 12$ & $184 \pm 27$ & $183 \pm 32$ & $224 \pm 32$ & $128 \pm 24$ \\
\hline $\mathrm{Sr}$ & $356 \pm 16$ & $392 \pm 5$ & $402 \pm 4$ & $376 \pm 20$ & $857 \pm 92$ & $469 \pm 13$ \\
\hline V & $132 \pm 23$ & $222 \pm 3$ & $254 \pm 6$ & $30.7 \pm 9$ & $31.7 \pm 10$ & $52.7 \pm 12$ \\
\hline $\mathrm{Y}$ & $15.0 \pm 5$ & $13.0 \pm 12$ & $16.8 \pm 10$ & $13.3 \pm 9$ & $13.3 \pm 9$ & $10.3 \pm 31$ \\
\hline $\mathrm{Zn}$ & $3443 \pm 27$ & $2912 \pm 32$ & $2971 \pm 24$ & $3748 \pm 53$ & $3303 \pm 42$ & $2259 \pm 26$ \\
\hline $\mathrm{Zr}$ & $165 \pm 32$ & $210 \pm 42$ & $232 \pm 27$ & $140 \pm 41$ & $204 \pm 53$ & $205 \pm 12$ \\
\hline
\end{tabular}


Table 3

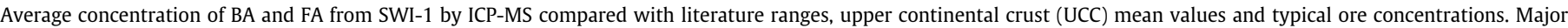
elements (from $\mathrm{SiO}_{2}$ to $\mathrm{P}_{2} \mathrm{O}_{5}$ ) are reported in $\mathrm{g} / 100 \mathrm{~g}$ of oxides, minor and trace elements (from $\mathrm{Ag}$ to $\mathrm{Zr}$ ) in $\mathrm{mg} / \mathrm{kg}$.

\begin{tabular}{|c|c|c|c|c|c|c|c|}
\hline \multirow[t]{2}{*}{ Element } & \multicolumn{2}{|c|}{$\begin{array}{l}\text { MSWI, Italy } \\
\text { This study }\end{array}$} & \multirow[t]{2}{*}{$\begin{array}{l}\text { Literature data }(B A)^{a} \\
\text { Min-max }\end{array}$} & \multirow[t]{2}{*}{$\begin{array}{l}\text { Literature data }(\mathrm{FA})^{\mathrm{a}} \\
\text { Min-max }\end{array}$} & \multirow[t]{2}{*}{$\begin{array}{l}\mathrm{UCC}^{\mathrm{b}} \\
\text { Average }\end{array}$} & \multirow[t]{2}{*}{$\begin{array}{l}\text { Ore concentration }{ }^{\mathrm{c}} \\
\text { Min-max }\end{array}$} & \multirow[t]{2}{*}{$\begin{array}{l}\text { Active mines (2013) in Fennoscandia } \\
\text { Min-max }\end{array}$} \\
\hline & $B A$ & $F A$ & & & & & \\
\hline $\mathrm{SiO}_{2}$ & 32.5 & 13.9 & $9.1-30.8(10)$ & $2.4-23.6(9)$ & 66.6 & - & - \\
\hline $\mathrm{TiO}_{2}$ & 1.24 & 1.42 & $0.3-1.8(10)$ & $0.53-1.5(8)$ & 0.64 & - & $1.67-11$ \\
\hline $\mathrm{Al}_{2} \mathrm{O}_{3}$ & 8.89 & 5.58 & $1.9-11.0(11)$ & $1.8-8.18(9)$ & 15.4 & - & - \\
\hline $\mathrm{FeO}$ & 9.84 & 1.99 & $0.4-15.0(11)$ & $0.6-4.83(9)$ & 5.04 & - & $27.2-53.9$ \\
\hline $\mathrm{CaO}$ & 23.4 & 38.6 & $1.2-24.0(11)$ & $8.6-32.2(9)$ & 3.59 & - & - \\
\hline $\mathrm{MnO}$ & 0.19 & 0.11 & $0.001-0.41(11)$ & $0.02-0.27(9)$ & 0.10 & - & $0.03-1.98$ \\
\hline $\mathrm{MgO}$ & 2.53 & 3.66 & $0.04-3.1(11)$ & $0.82-3.1(8)$ & 2.48 & $10-40$ & - \\
\hline $\mathrm{K}_{2} \mathrm{O}$ & 1.49 & 4.72 & $0.08-1.6(11)$ & $1.3-10.0(9)$ & 2.80 & - & - \\
\hline $\mathrm{Na}_{2} \mathrm{O}$ & 3.11 & 6.89 & $0.3-4.2(11)$ & $1.6-10.38(9)$ & 3.27 & - & - \\
\hline $\mathrm{P}_{2} \mathrm{O}_{5}$ & 2.18 & 1.45 & $0.1-2.4(9)$ & $0.4-2.49(8)$ & 0.15 & - & 1.15-17.63 \\
\hline $\mathrm{Ag}$ & 5.51 & 19.3 & $<0.29-36.9$ (3) & $3.9-34(3)$ & 0.05 & - & $1.3-151$ \\
\hline As & 11.9 & 21.1 & $0.12-189(12)$ & $0.7-307(4)$ & 4.80 & $1000-40,000$ & - \\
\hline $\mathrm{Au}$ & 0.44 & 0.58 & $<0.11-2.2(4)$ & $<1-2.2(2)$ & 0.002 & $<5-30$ & $0.008-5.2$ \\
\hline $\mathrm{Ba}$ & 1404 & 970 & $69-3990(12)$ & $12-1870(8)$ & 628 & 590,000 & - \\
\hline $\mathrm{Be}$ & 0.56 & - & $1.2-6(2)$ & $2.4-7.6(1)$ & 2.10 & $3000-50,000$ & - \\
\hline $\mathrm{Bi}$ & 2.28 & 51.2 & $0.35-57(2)$ & $6-150(3)$ & 0.16 & - & - \\
\hline Cd & 5.62 & 114 & $0.35-70.5(11)$ & $72-456(5)$ & 0.09 & $1000-10,000$ & - \\
\hline $\mathrm{Ce}$ & 31.8 & 20.0 & $15.1-51.0(10)$ & $2.85-18(5)$ & 63.0 & $18,000-300,000$ & - \\
\hline Co & 35.4 & 21.0 & $6-350(10)$ & $6.7-262(4)$ & 17.3 & $500-3000$ & $150-2300$ \\
\hline $\mathrm{Cr}$ & 367 & 635 & $20.4-3170(11)$ & $120-2026(5)$ & 92.0 & 310,000 & 200,000 \\
\hline Cs & 1.51 & 4.80 & $0.78-15.3(3)$ & $9.0-110(1)$ & 4.90 & - & - \\
\hline $\mathrm{Cu}$ & 3490 & 952 & $190-25,100(12)$ & $330-5530(9)$ & 28.0 & $5000-20,000$ & $1000-26,700$ \\
\hline Dy & 1.87 & 0.96 & $0.79-3(3)$ & $0.16(1)$ & 3.90 & $430-47,000$ & - \\
\hline $\mathrm{Er}$ & 1.26 & 0.60 & $0.72-2(3)$ & $0.39(1)$ & 2.30 & $13-29,000$ & - \\
\hline $\mathrm{Eu}$ & 0.92 & 0.71 & $0.25-1(5)$ & $0.06-2(2)$ & 1.00 & $220-1100$ & - \\
\hline Ga & 14.5 & 7.88 & $7.84-24(4)$ & $3-18(3)$ & 17.5 & $100-1000$ & - \\
\hline Gd & 2.43 & 1.29 & $1.7-5.03(3)$ & $0.59-2.6(2)$ & 4.00 & $650-21,000$ & - \\
\hline $\mathrm{Hf}$ & 2.70 & 1.44 & $2.33-42.0(2)$ & - & 5.30 & - & - \\
\hline Ho & 0.39 & 0.26 & $0.30-0.43(2)$ & $0.18(1)$ & 0.83 & $16-11,000$ & - \\
\hline La & 18.8 & 11.6 & $2-30.5(5)$ & $1.76-6.6(2)$ & 31.0 & $2600-180,000$ & - \\
\hline $\mathrm{Li}$ & 26.6 & 23.7 & - & $40-110(1)$ & 24.0 & - & - \\
\hline Lu & 0.17 & 0.08 & $0.02-0.17(2)$ & $<1(1)$ & 0.31 & $<2200$ & - \\
\hline Mo & 16.5 & 20.4 & $2.5-280(3)$ & $4.6-489(4)$ & 1.10 & $<10,000$ & $26-70$ \\
\hline $\mathrm{Nb}$ & 14.8 & 10.5 & $2-12(2)$ & $12-16(1)$ & 12.0 & $4100-21,000$ & $3400-3800$ \\
\hline $\mathrm{Nd}$ & 12.1 & 7.15 & $6.4-20(4)$ & $1.35-7(2)$ & 27.0 & $6000-98,000$ & - \\
\hline $\mathrm{Ni}$ & 224 & 85.9 & $7-4280(12)$ & $17-614(6)$ & 47.0 & $15,000-30,000$ & $700-73,300$ \\
\hline $\mathrm{Pb}$ & 1517 & 2987 & $74.7-13,700(12)$ & $640-5500(9)$ & 17.0 & $300,000-400,000$ & $4000-70,000$ \\
\hline $\operatorname{Pr}$ & 3.35 & 1.95 & $1.78-5.5(3)$ & $0.53(1)$ & 7.10 & $1600-33,000$ & - \\
\hline $\mathrm{Sb}$ & 119 & 1022 & $7.6-432(7)$ & $59-2107(6)$ & 0.40 & 27,000 & $1000-25,000$ \\
\hline Sc & 10.2 & 4.59 & $1.3-22(4)$ & $0.6-4(2)$ & 14.0 & $20-130,000$ & - \\
\hline $\mathrm{Sm}$ & 2.26 & 1.29 & $1.32-5(4)$ & $<0.1-1(2)$ & 4.70 & $690-16,000$ & - \\
\hline Sn & 201 & 713 & $2-470(6)$ & $240-5880(7)$ & 2.10 & 4000 & - \\
\hline $\mathrm{Sr}$ & 440 & 429 & $85-1000(9)$ & $150-740(7)$ & 320 & - & - \\
\hline Та & 1.12 & 1.19 & $2.47-14.2(4)$ & $1.2-43(1)$ & 0.90 & $<410$ & $260-310$ \\
\hline $\mathrm{Tb}$ & 0.41 & 0.29 & $0.18-3(4)$ & $0.07-2(2)$ & 0.70 & $45-53,000$ & - \\
\hline $\operatorname{Tm}$ & 0.16 & 0.08 & $0.01-0.18(2)$ & - & 0.30 & $3-4900$ & - \\
\hline $\mathrm{U}$ & 1.45 & 0.91 & $0.75-1.97(2)$ & - & 2.70 & - & 17 \\
\hline V & 196 & 19.7 & $20-122(6)$ & $<10-86(4)$ & 97.0 & $500-13,000$ & - \\
\hline W & 20.8 & 8.77 & $9.7-40.4(6)$ & $6.2-629(3)$ & 1.90 & $<15,000$ & - \\
\hline Y & 14.3 & 9.88 & $2.0-79(5)$ & $0.9-14(3)$ & 21.0 & - & - \\
\hline $\mathrm{Yb}$ & 1.10 & 0.52 & $0.55-5(3)$ & $0.20-2(3)$ & 1.96 & $3-34,000$ & - \\
\hline $\mathrm{Zn}$ & 3562 & 13,417 & $10-20,000(11)$ & $3800-16,800(8)$ & 67.0 & $50,000-150,000$ & $4400-110,000$ \\
\hline $\mathrm{Zr}$ & 108 & 71.4 & $41-1200(9)$ & $20-480(4)$ & 193 & - & 1600 \\
\hline
\end{tabular}

The "-" means data not available.

${ }^{a}$ The number of literature sources used to define the range in the tables is reported in parentheses. The sources were: Allegrini et al. (2014), Hasegawa et al. (2014), Sekito et

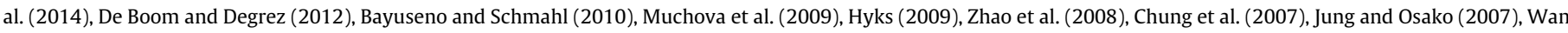
et al. (2006), Fujimori et al. (2004), Chandler et al. (1997), Kida et al. (1996).

b The upper continental crust (UCC) mean values are from Rudnick and Gao (2014).

c Ore concentrations are from Allegrini et al. (2014) and reference therein.

${ }^{\mathrm{d}}$ Concentration reference of active mines (2013) in Fennoscandia from Geological Survey of Finland (GTK-website: http://en.gtk.fi/).

As the annual flow evaluation needs data of high precision in order to minimise the calculation bias, we have considered the ICP MS results.

The following elements were selected for the annual flow analysis: the CRM elements $\mathrm{Be}, \mathrm{Co}, \mathrm{Cr}, \mathrm{Ga}, \mathrm{Mg}, \mathrm{Nb}, \mathrm{Sb}, \mathrm{W}$, including the REE group (from La to Lu plus Sc and Y), the precious metals gold
(Au) and silver (Ag), some metals of high economic importance, according the European Commission (2014), Al, Cu, Fe, $\mathrm{Li}, \mathrm{Mn}$, Mo, Ni, Sn, Ta, Ti, V and $\mathrm{Zn}$ and other metals, Ba, Bi, Hf, K, Pb, Rb, $\mathrm{Sr}, \mathrm{Tl}$ and $\mathrm{Zr}$.

Transfer ratios $(K)$ of selected CRM and other valuable metals were calculated by the following equations: 


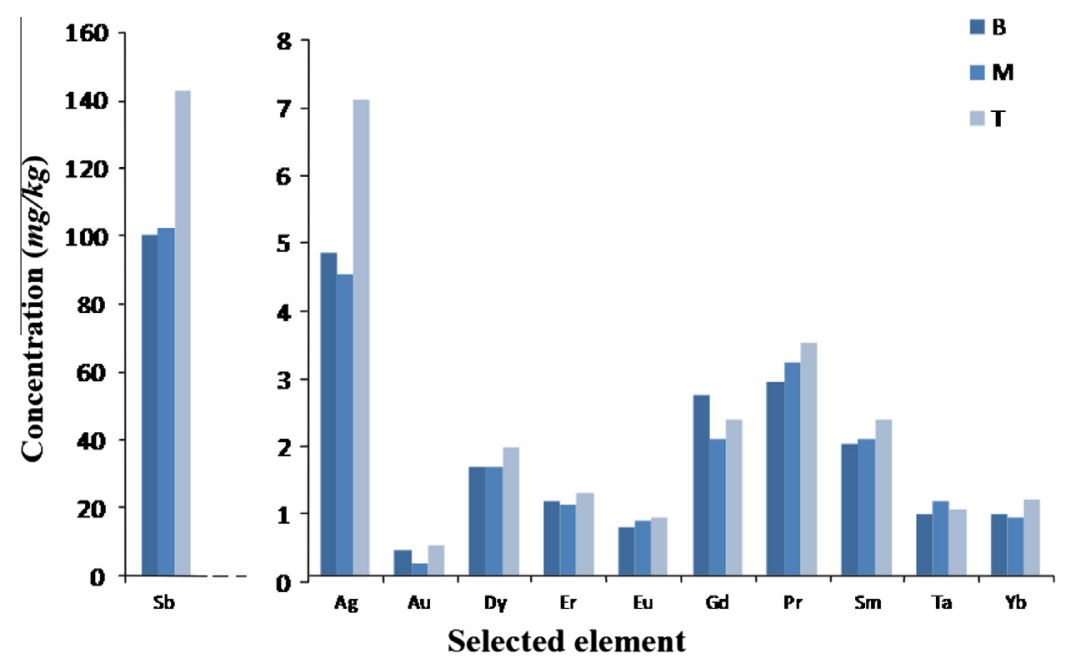

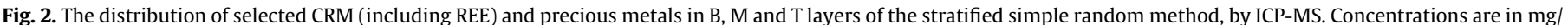
$\mathrm{kg}$.

$$
\begin{array}{ll}
K_{\mathrm{FA}} & \frac{F A(\%) \times C i_{\mathrm{FA}}(\mathrm{mg} / \mathrm{kg})}{\mathrm{BA}(\%) \times C i_{\mathrm{BA}}(\mathrm{mg} / \mathrm{kg})+\mathrm{FA}(\%) \times C i_{\mathrm{FA}}(\mathrm{mg} / \mathrm{kg})} \\
K_{\mathrm{BA}} & \frac{\mathrm{BA}(\%) \times C i_{\mathrm{BA}}(\mathrm{mg} / \mathrm{kg})}{\mathrm{BA}(\%) \times C i_{\mathrm{BA}}(\mathrm{mg} / \mathrm{kg})+\mathrm{FA}(\%) \times C i_{\mathrm{FA}}(\mathrm{mg} / \mathrm{kg})} \\
K_{\mathrm{BAf}} & \frac{\mathrm{BA}_{\mathrm{f}}(\%) \times C i_{\mathrm{BAf}}(\mathrm{mg} / \mathrm{kg})}{\mathrm{BA}(\%) \times C i_{\mathrm{BA}}(\mathrm{mg} / \mathrm{kg})}
\end{array}
$$

where $\mathrm{BA} \%$ and $\mathrm{FA} \%$ are the mass flow in percent of the bottom and fly ash residues in the final solid output, respectively. $C i_{\mathrm{FA}}$ and $C i_{\mathrm{BA}}$ are the concentration of the element $i$ in the respective residue. $K$ from FA $\left(K_{\mathrm{FA}}\right)$ and $\mathrm{BA}\left(K_{\mathrm{BA}}\right)$ final outputs were calculated, in a similar way adopted by Zhang et al. (2008a) for the evaluation of the distribution of heavy metals between different types of residues. Eq. (5) allows us to calculate the $K$ among different fractions of BA $\left(K_{\mathrm{BAf}}\right)$.

\section{Results and discussion}

\subsection{Bottom ash}

$\mathrm{SiO}_{2}$ and $\mathrm{CaO}$ are the main oxides in $\mathrm{BA}$ (Table 1 ), with concentrations higher than $30 \mathrm{~g} / 100 \mathrm{~g}$ and $20 \mathrm{~g} / 100 \mathrm{~g}$, respectively. The BA contain about $10 \mathrm{~g} / 100 \mathrm{~g}$ of iron (expressed as $\mathrm{Fe}_{2} \mathrm{O}_{3}$ ), about $8 \mathrm{~g} / 100 \mathrm{~g}$ of $\mathrm{Al}_{2} \mathrm{O}_{3}$. The contribution of titanium, aluminium, iron and manganese oxides is similar between SWI 1 and SWI 2. The mean values are quite similar and the relative standard deviation ranges between $10 \%$ and $40 \%$, pointing that the material is rather homogeneous. This is probably due to similar waste input and combustion conditions (De Boom and Degrez, 2012). The amount of $\mathrm{MgO}$ is higher in SWI 1 rather than SWI 2, with a large variance calculated for the former. Magnesium could derive from metallurgical processes, electronic devices, agricultural fertilizer, chemicals and pharmaceuticals. Therefore it is worthy to note that the waste input to SWI 1 comprises also pharmaceutical/hospital waste.

XRF trace elements analyses of BA samples from SWI 1 and SWI 2 (Table 2) show high concentrations of the following heavy metals (in decreasing order of abundance): $\mathrm{Zn}, \mathrm{Cu}, \mathrm{Ba}, \mathrm{Cr}, \mathrm{Pb}, \mathrm{Sn}$ and $\mathrm{V}$. Each sample contains more than $2 \mathrm{~g} / \mathrm{kg}$ of $\mathrm{Zn}$ and $\mathrm{Cu}$, over $1 \mathrm{~g} / \mathrm{kg}$ Ba. Many trace elements show high standard deviation probably due to a random error during sampling operations, e.g. the presence of sub millimeter metallic scraps can affect lead, tin and zinc concentrations. However trace elements concentration are quite similar in SWI 1 and SWI 2 BA residues, only V, Ni and La, show higher values in SWI 1 relative to SWI 2.

ICP MS data for SWI 1 BA (Table 3) show a silver mean concentration of $5.5 \mathrm{mg} / \mathrm{kg}, 0.4 \mathrm{mg} / \mathrm{kg} \mathrm{Au}, 0.6 \mathrm{~g} / \mathrm{kg}$ as sum of selected CRM (Be, Co, Cr, Ga, Nb, Sb, W), over $0.1 \mathrm{~g} / \mathrm{kg} \mathrm{REY} \mathrm{(REE} \mathrm{+} \mathrm{Sc} \mathrm{+} \mathrm{Y),} 7.7 \mathrm{~g} / \mathrm{kg}$ other metals with high economic importance $(\mathrm{Cu}, \mathrm{Li}, \mathrm{Mo}, \mathrm{Ni}, \mathrm{Sn}, \mathrm{Ta}$, $\mathrm{V}$ and $\mathrm{Zn}$ according to EC, 2014). Cerium is the prevailing element of the REE group ( $31.8 \mathrm{mg} / \mathrm{kg}$ ), chromium and antimony are the most abundant amongst CRM elements (0.37 and $0.12 \mathrm{~g} / \mathrm{kg}$, respectively). For most of trace elements ICP MS measured concentrations are in good agreement with XRF data of this study (see Table 2) and within the ranges quoted in the literature (Table 3 ). Moreover, the untreated samples composition is comparable to the Danish and Swiss treated residues, analysed by Allegrini et al. (2014) and Morf et al. (2013), revealing that the post treatment (i.e., separation between ferrous and non ferrous material) of BA leads to a weak mineral beneficiation.

3.1.1. Gravitative selection control on partitioning of critical elements

The simple gravitative selection of the stockpile drives the distribution of the elements. The total content of $\mathrm{Zn}, \mathrm{Cu}$ and $\mathrm{Ba}$ is more abundant in the B layer as far over $1 \mathrm{~g} / \mathrm{kg}$. Ni, $\mathrm{V}$ and $\mathrm{Zr}$ concentrations range between 0.10 and $0.25 \mathrm{~g} / \mathrm{kg}$, with the $\mathrm{T}$ layer enriched compared to the others.

Fig. 2 shows the elements distribution within the sampled layers of SWI 1: Ag, Ce, La, Nb, Sb and Mo preferentially partition in the finer fractions, as the most of REE, whereas $\mathrm{Cr}$ and $\mathrm{Gd}$ are rel atively enriched into the coarser fraction of the bottom layer. About 0.5 $\mathrm{mg} / \mathrm{kg}$ gold and $7 \mathrm{mg} / \mathrm{kg}$ silver are found in the top layer, as well around $15 \mathrm{mg} / \mathrm{kg} \mathrm{La}, \mathrm{Nb}$ and $\mathrm{Nd}$. Conversely, Au, Co, Ga, Sc, Ta and Y seem to be less influenced by grain size.

These results suggest that the potential recovery of some elements could be simplified by treating specific grain size fractions, readily distinguishable on the storage piles. XRF analyses on sieved samples are provided in the S.1 of supplementary materials to further confirm the hypothesis of the grain size control on the distribution of some CRM. Therefore, the visual aid sampling may represent a good choice when any mineral beneficiation is required before the elements recovery is planned from low concentration streams. Moreover this primary separation onsite, which could be performed by unskilled operators, is cost effective because require no further devices, whose implementation could be expen sive especially for old MSWI systems. In Section 3.3 we report an estimation of annual substance flow for BA sampled fractions. 


\subsection{Fly ash}

The major constituents of FA samples (Table 1$)$ are $\mathrm{CaO}(>30 \mathrm{~g} /$ $100 \mathrm{~g}$ ), $\mathrm{SiO}_{2}\left(>10 \mathrm{~g} / 100 \mathrm{~g}\right.$ ), $\mathrm{Al}_{2} \mathrm{O}_{3}, \mathrm{MgO}$ and $\mathrm{K}_{2} \mathrm{O}$ (around $5 \mathrm{~g} / 100 \mathrm{~g}$ ), $\mathrm{Fe}_{2} \mathrm{O}_{3}, \mathrm{TiO}_{2}$ and $\mathrm{P}_{2} \mathrm{O}_{5}(<3 \mathrm{~g} / 100 \mathrm{~g})$. Lithophile elements such as silicon, aluminium and calcium, which form very stable oxides and anions and have high boiling point are more concentrated in BA rather than in FA (see Table 1).

FA contain a high amount of the CRM elements $\mathrm{Sb}$ (around $0.1 \mathrm{~g} / \mathrm{kg}$ ) and $\mathrm{Cr}$ (around $0.6 \mathrm{~g} / \mathrm{kg}$ ), as well as the base metals $\mathrm{Zn}$ $(>10 \mathrm{~g} / \mathrm{kg})$ and $\mathrm{Pb}(>2 \mathrm{~g} / \mathrm{kg})$, in both incinerator plants (Table 4). Such values are one to two orders of magnitude higher than those of others CRM and valuable metals. Elements like $\mathrm{Bi}, \mathrm{Cd}$ and $\mathrm{Rb}$ range between 0.04 and $0.12 \mathrm{~g} / \mathrm{kg}, \mathrm{Cu}$ and $\mathrm{Sn}$ from 0.7 to $0.9 \mathrm{~g} / \mathrm{kg}$.

FA residues from the two MSWI facilities show a silver mean concentration of $19.3 \mathrm{mg} / \mathrm{kg}, 48 \mathrm{mg} / \mathrm{kg}$ as the sum of selected CRM (Co, Ga, Nb, W), $62 \mathrm{mg} / \mathrm{kg}$ REY (REE + Sc + Y), $150 \mathrm{mg} / \mathrm{kg}$ other metals with high economic importance ( $\mathrm{Li}, \mathrm{Mo}, \mathrm{Ni}$, Ta and $\mathrm{V}$ according to EC, 2014). FA present very similar concentrations between SWI 1 and SWI 2; the MgO exception is probably due to the different waste input composition, as suggested for BA (see Table 1).

Results are in good agreement with the available data from literature on furnace ashes from Belgian MSWI plants (De Boom and Degrez, 2012) and are within the compositional ranges of the over all fly ash data, which are provided in Table 3.

\subsection{Estimated annual flow of SWI 1 residues}

With the simple mass balance given by the Eqs. (1) and (2), we estimated the yearly flows of selected metals, in $\mathrm{kg} / \mathrm{a}$, for the SWI 1 (Table 5). Only ICP MS data was used for calculations. The estimated annual flows are reported both for BA and FA, which are separately stored and managed in common incinerator plants, in order to determine the most useful residue for the recovery of certain CRM. The owners of the incinerator plant provided the total BA and FA output, as reported in Section 2.1.

For BA residues we determined a total flow of more than $350 \mathrm{t} / \mathrm{a}$ $\mathrm{Mg}, 8.5 \mathrm{t} / \mathrm{a} \mathrm{Cr}, 4.3 \mathrm{t} / \mathrm{a} \mathrm{Co}$, nearly $3 \mathrm{t} / \mathrm{a} \mathrm{Sb}$. The overall annual flow of the light REE (La, Ce, Pr, Nd, Sm, Eu, Gd) plus Sc and Y exceeds $2 \mathrm{t} / \mathrm{a}$; whereas the flow of heavy REE (Tb, Dy, Ho, Er, Tm, Yb and Lu) is around $0.1 \mathrm{t} / \mathrm{a}$, being $\mathrm{Yb}$ the most significant flow. The annual flow analysis even shows considerable amount of other CRM: W (0.5 t) a), Ga and $\mathrm{Nb}(0.3 \mathrm{t} / \mathrm{a})$. The flow for precious metals is approximately $0.01 \mathrm{t} / \mathrm{a}$ gold and $0.12 \mathrm{t} / \mathrm{a}$ silver. Because of the small amount of the BA test portions (tens of kilograms), the contribution of "nuggets" to the total elements content cannot be evaluated and the average value of the real flows could be underestimated.

Table 5 shows a flow of $79 \mathrm{t} / \mathrm{a} \mathrm{Mg}, 2.4 \mathrm{t} / \mathrm{a} \mathrm{Sb}$, around $1 \mathrm{t} / \mathrm{a} \mathrm{Cr}$, 0.05 t/a Ce, 0.04 t/a Co for FA residues. Other metals have relatively high flows, in decreasing order: $\mathrm{Bi}, \mathrm{Tl}, \mathrm{Zn}, \mathrm{Sn}, \mathrm{Ag}, \mathrm{Au}, \mathrm{Mo}$ and Ta. In the FA the contribution of nuggets on the total content of precious and valuable metals could be negligible due to the sample and grain size homogeneity. The FA annual flows are about one order of magnitude lower than BA flows because of the difference between the total mass output of fly ashes and bottom ashes.

The origins in the input sources of the elements were not evaluated in this study. The separate collection of waste from electrical and electronic equipment (WEEE), among the others, is adopted in the region, but the presence of REE and other specific elements might reveal a poor upstream separation. The evaluation of elemental flows in final waste outputs discloses deficiency in the separate collection system.

The overall flows data presented in this study are in good agree ment with the results of Morf et al. (2013), although the latter report an estimated annual flow for the total waste input of a Swiss
Table 4

Trace elements concentration (averages) of FA from SWI-1 and SWI-2, by ICP-MS Values are reported in $\mathrm{mg} / \mathrm{kg}$.

\begin{tabular}{|c|c|c|}
\hline Element & FA SWI-1 & FA SWI-2 \\
\hline $\mathrm{Ag}$ & 22.5 & 16.1 \\
\hline As & 21.2 & 21.0 \\
\hline $\mathrm{Au}$ & 0.71 & 0.45 \\
\hline $\mathrm{Ba}$ & 1088 & 852 \\
\hline $\mathrm{Bi}$ & 63.4 & 39.0 \\
\hline $\mathrm{Cd}$ & 121 & 107 \\
\hline $\mathrm{Ce}$ & 19.0 & 20.9 \\
\hline Co & 21.3 & 20.7 \\
\hline $\mathrm{Cr}$ & 328 & 941 \\
\hline Cs & 4.81 & 4.80 \\
\hline $\mathrm{Cu}$ & 993 & 910 \\
\hline Dy & 0.83 & 1.10 \\
\hline $\mathrm{Er}$ & 0.59 & 0.61 \\
\hline $\mathrm{Eu}$ & 0.72 & 0.70 \\
\hline $\mathrm{Ga}$ & 7.98 & 7.77 \\
\hline Gd & 1.24 & 1.33 \\
\hline $\mathrm{Hf}$ & 1.69 & 1.19 \\
\hline $\mathrm{Hg}$ & 0.01 & 0.00 \\
\hline Ho & 0.30 & 0.21 \\
\hline $\mathrm{La}$ & 11.5 & 11.7 \\
\hline $\mathrm{Li}$ & 24.0 & 23.3 \\
\hline $\mathrm{Lu}$ & 0.07 & 0.09 \\
\hline Mo & 23.1 & 17.8 \\
\hline $\mathrm{Nb}$ & 10.0 & 10.9 \\
\hline $\mathrm{Nd}$ & 6.39 & 7.91 \\
\hline $\mathrm{Ni}$ & 95.2 & 76.4 \\
\hline $\mathrm{Pb}$ & 2388 & 3586 \\
\hline $\operatorname{Pr}$ & 1.70 & 2.21 \\
\hline $\mathrm{Rb}$ & 95.8 & 106 \\
\hline $\mathrm{Sb}$ & 994 & 1050 \\
\hline Sc & 4.74 & 4.44 \\
\hline Se & 15.1 & 11.0 \\
\hline Sm & 1.17 & 1.42 \\
\hline Sn & 760 & 665 \\
\hline $\mathrm{Sr}$ & 394 & 463 \\
\hline Тa & 1.28 & 1.09 \\
\hline $\mathrm{Tb}$ & 0.27 & 0.31 \\
\hline Th & 2.33 & 2.77 \\
\hline $\mathrm{Tl}$ & 1.08 & 0.93 \\
\hline $\mathrm{Tm}$ & 0.07 & 0.09 \\
\hline $\mathrm{U}$ & 0.83 & 0.99 \\
\hline V & 17.2 & 20.1 \\
\hline W & 9.40 & 8.14 \\
\hline $\mathrm{Y}$ & 9.87 & 9.89 \\
\hline $\mathrm{Yb}$ & 0.43 & 0.60 \\
\hline $\mathrm{Zn}$ & 14,837 & 11,998 \\
\hline $\mathrm{Zr}$ & 76.4 & 66.5 \\
\hline
\end{tabular}

incinerator plant. By multiplying their measured concentrations with the inferred output flow of the Swiss facility (40 $60 \mathrm{k}$ ton per year), the flows of elements range in the same order of magnitude than the output flows of the Italian incinerator plant. As an example, flows from 0.01 to $0.03 \mathrm{t} / \mathrm{a} \mathrm{Au}, 0.450 .65 \mathrm{t} / \mathrm{a} \mathrm{Co}, 0.280 .43$ $\mathrm{t} / \mathrm{a} \mathrm{Nd}$ can be found in the output materials and these figures are comparable with values reported in Table 5 .

Considering 46 active MSWI plants in Italy during 2013 (ISPRA, 2013), the total solid waste output in Italy is approximately 1.8 million tons and the national substance flow of selected precious metals, CRM and other elements can be estimated. 4500 ton $\mathrm{Cu}$, 130 ton of total REE and 0.5 ton Au might be potentially recovered from BA, near the projected values reported in Swiss and Denmark by Morf et al. (2013) and Allegrini et al. (2014), respectively; while huge amounts of $\mathrm{Zn}(6700 \mathrm{t})$ and $\mathrm{Sb}(500 \mathrm{t})$ are in the FA output.

\subsection{Transfer coefficients of SWI 1 residues}

Transfer coefficients were used to determine the distribution of specific elements between BA and FA output fractions (B, $M, T)$, 
Table 5

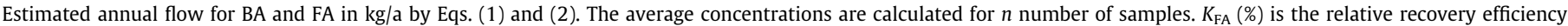

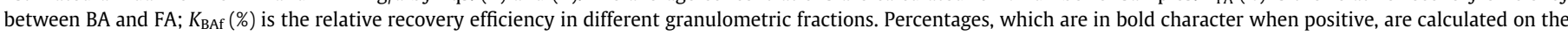
basis of transfer coefficients (Eqs. (3)-(5)).

\begin{tabular}{|c|c|c|c|c|c|c|c|}
\hline & \multirow{2}{*}{$\begin{array}{l}\text { Flow }(\mathrm{kg} / \mathrm{a}) \\
\text { Bulk BA }(n=9)^{\mathrm{a}}\end{array}$} & \multicolumn{3}{|c|}{$K_{\mathrm{BAf}}(\%)$} & \multirow{2}{*}{$\begin{array}{l}\text { Flow }(\mathrm{kg} / \mathrm{a}) \\
\text { Bulk FA }(n=2)^{\text {a }}\end{array}$} & \multicolumn{2}{|c|}{$K_{\mathrm{FA}}(\%)$} \\
\hline & & B & M & $\mathrm{T}$ & & $O_{\mathrm{FA}}$ & $O_{\mathrm{FA}}=\mathrm{O}_{\mathrm{BA}}$ \\
\hline \multicolumn{8}{|c|}{ CRM } \\
\hline $\mathrm{Mg}$ & $354,000 \pm 5600$ & 0 & -6 & +7 & $78,500 \pm 350$ & -78 & +113 \\
\hline $\mathrm{Cr}$ & $8500 \pm 400$ & +16 & -4 & -13 & $800 \pm 53$ & -92 & -10 \\
\hline $\mathrm{Co}$ & $4300 \pm 3000$ & -43 & -40 & +83 & $42 \pm 11$ & -98 & -90 \\
\hline $\mathrm{Sb}$ & $266 \pm 440$ & -13 & -11 & +24 & $2401 \pm 60$ & +3 & +767 \\
\hline $\mathrm{Ce}$ & $730 \pm 53$ & -1 & 0 & +3 & $46 \pm 7.0$ & -94 & -40 \\
\hline W & $483 \pm 13$ & -1 & +4 & -4 & $22 \pm 4.1$ & -95 & -57 \\
\hline $\mathrm{La}$ & $430 \pm 38$ & -2 & -9 & +14 & $27 \pm 0.1$ & -94 & -40 \\
\hline $\mathrm{Ga}$ & $330 \pm 22$ & -6 & 0 & +6 & $19 \pm 0.2$ & -94 & -45 \\
\hline $\mathrm{Nb}$ & $330 \pm 49$ & -3 & +9 & -6 & $24 \pm 0.2$ & -93 & -30 \\
\hline $\mathrm{Y}$ & $321 \pm 33$ & -7 & -8 & +15 & $23 \pm 1.0$ & -92 & -31 \\
\hline $\mathrm{Nd}$ & $270 \pm 35$ & -11 & -4 & +11 & $15 \pm 1.0$ & -94 & -48 \\
\hline Sc & $230 \pm 11$ & +4 & -4 & +4 & $11 \pm 0.5$ & -96 & -57 \\
\hline $\operatorname{Pr}$ & $70 \pm 10$ & -14 & 0 & +14 & $3.1 \pm 0.2$ & -95 & -57 \\
\hline Gd & $50 \pm 11$ & +20 & -20 & 0 & $2.1 \pm 0.4$ & -97 & -60 \\
\hline $\mathrm{Sm}$ & $50 \pm 6$ & -6 & -4 & +10 & $2.1 \pm 0.1$ & -96 & -60 \\
\hline Dy & $40 \pm 7$ & -25 & -25 & 0 & $1.0 \pm 0.1$ & -97 & -75 \\
\hline $\mathrm{Yb}$ & $24 \pm 3.3$ & -4 & -8 & +17 & $1.0 \pm 0.1$ & -95 & -58 \\
\hline $\mathrm{Er}$ & $20 \pm 3.7$ & 0 & 0 & $+\mathbf{5 0}$ & $1.0 \pm 0.2$ & -95 & -50 \\
\hline $\mathrm{Eu}$ & $20 \pm 2.6$ & -50 & 0 & 0 & $1.0 \pm 0.1$ & -90 & -50 \\
\hline $\mathrm{Be}$ & $11 \pm 1.0$ & -27 & -9 & +36 & - & - & \\
\hline $\mathrm{Tb}$ & $9.0 \pm 1.0$ & -11 & -11 & +11 & $0.6 \pm 0.02$ & -92 & -33 \\
\hline Ho & $8.0 \pm 1.3$ & 0 & -13 & +13 & $0.6 \pm 0.03$ & -97 & -67 \\
\hline $\mathrm{Lu}$ & $3.7 \pm 0.5$ & -5 & -8 & +16 & $0.1 \pm 0.001$ & -97 & -67 \\
\hline $\mathrm{Tm}$ & $3.6 \pm 0.4$ & -6 & -6 & +17 & $0.2 \pm 0.01$ & -97 & -67 \\
\hline \multicolumn{8}{|c|}{ Valuable metals } \\
\hline $\mathrm{Fe}$ & $1,500,000 \pm 31,700$ & -2 & +9 & -7 & $39,000 \pm 1300$ & -97 & -76 \\
\hline $\mathrm{Al}$ & $1,200,000 \pm 26,400$ & +5 & -6 & +1 & $66,500 \pm 2100$ & -95 & -47 \\
\hline $\mathrm{Ti}$ & $145,000 \pm 5170$ & +6 & -6 & 0 & $19,000 \pm 440$ & -88 & +26 \\
\hline $\mathrm{Cu}$ & $81,000 \pm 7350$ & -11 & +12 & -2 & $2400 \pm 50$ & -97 & -72 \\
\hline $\mathrm{Zn}$ & $69,500 \pm 3920$ & +7 & -4 & -4 & $36,000 \pm 200$ & -52 & +396 \\
\hline $\mathrm{Mn}$ & $24,000 \pm 495$ & -3 & -3 & +5 & $1650 \pm 23$ & -93 & -34 \\
\hline $\mathrm{Ni}$ & $5200 \pm 346$ & -4 & -6 & +10 & $230 \pm 9.2$ & -95 & -58 \\
\hline $\mathrm{V}$ & $4200 \pm 570$ & -50 & -44 & +94 & $41 \pm 3.5$ & -98 & -91 \\
\hline Sn & $3680 \pm 140$ & +16 & -18 & +2 & $1840 \pm 14$ & -57 & +379 \\
\hline $\mathrm{Li}$ & $610 \pm 38$ & +2 & -7 & +7 & $57 \pm 0.7$ & -91 & -10 \\
\hline Mo & $380 \pm 22$ & -5 & -8 & +13 & $55 \pm 1.6$ & -85 & +39 \\
\hline $\mathrm{Ag}$ & $120 \pm 41$ & -8 & -17 & +33 & $54 \pm 0.3$ & -51 & +333 \\
\hline $\mathrm{Ta}$ & $25 \pm 5.5$ & -8 & +8 & -4 & $3.0 \pm 0.1$ & -87 & +16 \\
\hline $\mathrm{Au}$ & $10 \pm 3.7$ & +10 & -40 & +20 & $1.7 \pm 0.2$ & -85 & +60 \\
\hline \multicolumn{8}{|c|}{ Other metals } \\
\hline K & $220,000 \pm 17,400$ & +2 & -8 & +7 & $86,500 \pm 600$ & -62 & +276 \\
\hline $\mathrm{Pb}$ & $34,600 \pm 7120$ & -2 & -1 & +2 & $5770 \pm 52$ & -83 & +60 \\
\hline $\mathrm{Ba}$ & $32,400 \pm 1050$ & -2 & -1 & +3 & $2630 \pm 332$ & -92 & -22 \\
\hline $\mathrm{Sr}$ & $10,200 \pm 700$ & -7 & -1 & +2 & $950 \pm 14$ & -90 & -10 \\
\hline $\mathrm{Zr}$ & $2630 \pm 1200$ & -19 & +2 & +18 & $184 \pm 38$ & -91 & -33 \\
\hline $\mathrm{Rb}$ & $790 \pm 65$ & -13 & -9 & +6 & $230 \pm 2.2$ & -66 & +181 \\
\hline $\mathrm{Cd}$ & $122 \pm 24$ & -16 & -4 & +19 & $291 \pm 6.1$ & +139 & +2209 \\
\hline $\mathrm{Hf}$ & $60 \pm 24$ & -17 & 0 & +17 & $4.0 \pm 0.8$ & -94 & -50 \\
\hline $\mathrm{Bi}$ & $50 \pm 15$ & +40 & -40 & -40 & $150 \pm 9.5$ & +119 & +2840 \\
\hline $\mathrm{Tl}$ & $3.0 \pm 1.5$ & 0 & 0 & +33 & $2.6 \pm 0.07$ & -13 & +733 \\
\hline
\end{tabular}

a Estimated average annual flow and uncertainty are calculated also with replicates values of the sample measurement.

which are shown in Table 5 as relative percentage. These data may provide information on which grain size fraction is more promising for the eventual element recovery.

The calculated transfer coefficients (see Table S.2 in the supplementary materials) by Eqs. (3) and (4) reveal that $\mathrm{Cr}, \mathrm{Co}, \mathrm{Cu}, \mathrm{Mn}, \mathrm{Zr}$ and other base metals are found primarily in the $\mathrm{BA}$, whereas the volatile elements (e.g.: $\mathrm{Zn}, \mathrm{Sb}, \mathrm{Cd}$ and $\mathrm{Bi}$ ) are more distributed between BA and FA, as observed by others (e.g.: Morf et al., 2013; Astrup et al., 2011; Zhang et al., 2008a).

The recovery efficiency of FA on the basis of the relative mass output flows $\left(O_{\mathrm{FA}}\right)$ seems to be very low, with almost all negative values. However, FA residues are enriched in volatile elements such as $\mathrm{Bi}, \mathrm{Cd}$ and $\mathrm{Sb}$ despite the mass output difference. Most of the CRM, but Sb, preferentially partitions into the BA (Fig. 3).
Silver, gold and other valuable metals (i.e., Bi, Mo, Sn, Ta, Zn) have rather high transfer coefficients to FA. Furthermore, hypothe sizing a recovery process with the same mass volume of BA and FA $\left(O_{\mathrm{FA}}=O_{\mathrm{BA}}\right.$ in Table 5), the relative efficiency from FA residues is significantly higher for $\mathrm{Bi}, \mathrm{Cd}$ and $\mathrm{Sb}$ than the same elements from BA; moreover, for elements like $\mathrm{Zn}, \mathrm{Sn}, \mathrm{Ag}, \mathrm{Mg}$ and Au the recovery per formance is improved $(396 \%, 379 \%, 333 \%, 113 \%$ and $60 \%$, respectively).

We determined the transfer coefficients for BA in different granulometric fractions ( $T_{\mathrm{BAf}}$ ) following the Eq. (5). The percentage represents the enrichment or the depletion of the concentration with respect to the bulk BA content. The CRM show a relative enrichment in the top layer, except for chromium, niobium and tungsten. 

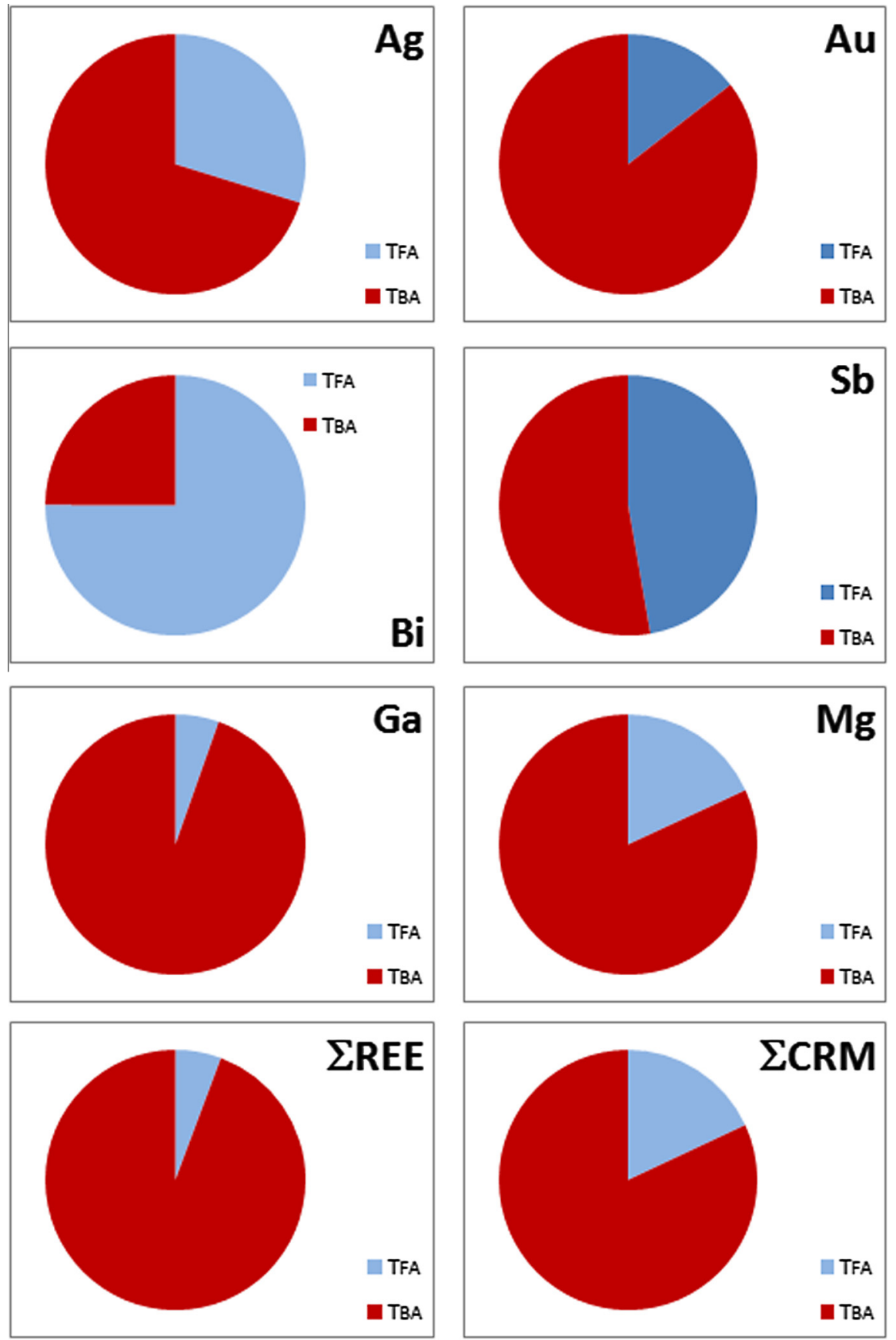

Fig. 3. Distribution of selected CRM between BA and FA final outputs calculated following Eqs. (3) and (4).

Precious and other valuable elements ( $\mathrm{Ag}, \mathrm{Be}, \mathrm{Co}, \mathrm{Sb}$ and $\mathrm{V}$ ) are more abundant in the finest fraction of $\mathrm{BA}$, while $\mathrm{Bi}, \mathrm{Cr}$ and $\mathrm{Zn}$ are enriched in the coarser BA. REE are preferentially portioned in the finer BA, except for Gd that it is enriched in the coarser BA. Euro pium, dysprosium and scandium are dispersed between fractions. Similar percentages or positive values both for B and T layers indicate the absence of a granulometric control for Au, Sc and Sn. The results indicate that a simple separation procedure of the fresh and untreated BA may lead to an increase of the relative recovery efficiency up to $94 \%$ for certain elements.

It is important to highlight that the accumulation and concentration of elements in output fractions are not due to the different ageing of sampled materials. The sampled stockpile was representative of two months deposition with high deposition rate. Several authors (e.g.: Meima and Comans, 1999; Cornelis et al., 2008; Santos et al., 2013) investigated bottom and fly ashes in different stage of ageing in order to assess the environmental risk and leach ing properties. They pointed out that aged bottom and fly ashes always show an enrichment of heavy metals, such as Be, Co, Mo, Sb, $\mathrm{V}, \mathrm{W}$ and $\mathrm{Zn}$. In this study we found higher content of these metals preferentially in finer fractions or $\mathrm{T}$ layers, which would be rather younger levels.

\section{5. "Urban" ore deposits as a potential target for raw materials supply}

In Table 3 the average values of SWI 1 BA and FA ("urban" ore), by ICP MS, are compared with the average upper continental crust (UCC) values (from Rudnick and Gao, 2014) and with typical values 
of concentrated ores (from Allegrini et al., 2014 and reference therein). Most of analysed CRM, including REE, show concentrations in the "urban ore" comparable with UCC values. Zinc, tin, antimony, sulfur, lead, copper, cadmium, bismuth, gold, silver concentrations are one order of magnitude higher than the UCC. Compared with UCC, interesting amount of vanadium and strontium are found in BA; chromium, silver and tin in FA. However, the concentration levels are by far lower than typical levels in concentrated ores, with the exception of copper (whose concentration is close to the concentrated ore values) and magnesium (only one order of magnitude lower than the low grade concentration).

As a qualitative index to evaluate economic feasibility of urban ore deposits as an alternative source of supply for Europe, we compare the MSWI residues concentrations with reference values from the Geological Survey of Finland (GTK) reports of active mines in Fennoscandia during 2013. The minimum concentration for naturally occurring silver is $1.3 \mathrm{~g} / \mathrm{t}$ (in the Aitik Nautanen metallogenic area), while this study shows a silver grade of $5.5 \mathrm{~g} / \mathrm{t}$ in the urban ore. Likewise, copper and zinc oxides have a minimum concentration of $0.01 \mathrm{~g} / 100 \mathrm{~g}$ and $0.4 \mathrm{~g} / 100 \mathrm{~g}$, respectively; the concentrations resulted from this study indicate occurrences of $0.03 \mathrm{~g} /$ $100 \mathrm{~g} \mathrm{Cu}$ in BA residues and $1.3 \mathrm{~g} / 100 \mathrm{~g} \mathrm{Zn}$ in FA residues. Lead, molybdenum and nickel are also close to the reported values for active mines in Fennoscandia; the concentration of some CRM and other base metals in MSWI outputs can be compared to a depleted ore in Europe and to polymetallic deposits (e.g., $\mathrm{Cu}, \mathrm{Cr}$, $\mathrm{Co}, \mathrm{Sn}, \mathrm{Ni}$ and $\mathrm{Zn}$ ) in China and India (Dachang, Zhaokalong and Koira Noamundi metallogenic areas; Li et al., 2013; Mohapatra et al., 2009; Jiang et al., 1999).

REE concentrations appear too low in the "urban ore" to be considered as a potential target for the recovery. The total content of rare earths as oxides (TREO) has to be in the range of $0.53 \%$ today to allow an economic exploitation. For example, the Kvanefjeld mining field contains $1.35 \%$ of TREO (www.ggg.gl), which is higher than the TREO content of the MSWI residues (about $0.01 \%$ ).

Although the urban mining as a source of critical elements is gaining increasing interest, at present the recovery of these materials does not seem feasible (Morf et al., 2013). Furthermore, apply ing the existing technologies for metal recovery would be not economic, especially when a large amounts of impure metals and strong alkaline conditions are found, such as in MSWI residues.

However, the urban ore deposit has the advantage of being already in granular form and leads to a limited environmental impact (or perhaps reduces it), in contrast with the natural ore deposit that may require lengthy and expensive operations: i.e., obtain concessions, remove the overburden, concentrate the mineral ore and restore the natural area. From this point of view, the efforts in the development of urban mine plans in order to recover valuable metals have to be increased.

The concentration of metals of environmental concern, e.g. Ba, $\mathrm{Cd}, \mathrm{Pb}, \mathrm{Mo}$ and the antimony itself, is over the minimum range of concentration of active mines (Table 3 ). This may represent an advantage for their recovery, but leaching properties of solid residues and, consequently, the risk for contamination should be accounted.

\section{Conclusions}

In the near future incineration processes will continue to be an important part of the waste management system along with recy cling and waste disposal. As a consequence, the governance of the solid residues will remain a general concern. Our working hypoth esis considers the solid residues as an unconventional source of CRM. The recovery of precious metals from MSWI residues might be an attractive option if the growing demand for raw materials will confront with their supply risk related to the instability of international markets. The main results of this study are:

1. The analysed bottom and fly ashes from two grate furnace incinerators confirm the presence of CRM and other valuable elements in concentration comparable with a low grade ore deposit (e.g.: magnesium and copper).

2. A simple mass balance for untreated bottom and fly ash residues indicates significant amounts per year of critical elements and other metals of economic interest, such as antimony, cobalt, copper, magnesium and zinc. Furthermore, the transfer coefficients allow to identify added value products, which could be processed for further mineral upgrading and recovery with the existing technologies.

3. There is a grain size control over the distribution of $\mathrm{Ag}, \mathrm{Sb}, \mathrm{Ce}$, $\mathrm{La}, \mathrm{Nb}, \mathrm{Ni}, \mathrm{V}$ which are enriched in the fine grained portion, whereas $\mathrm{Gd}, \mathrm{Cr}, \mathrm{Sc}, \mathrm{W}$ and Y preferentially partition into the coarser fraction of the residues.

4. The grain size fractions of bottom ash, commonly stored in stockpiles, are readily distinguishable at the storage site. This evidence permits a simple and cost effective separation strategy easy to implement at the plant scale. Such operation can be performed by less trained operators and may lead to an increase of the relative recovery efficiency up to $83 \%$ for CRM elements.

\section{Acknowledgements}

This study is co funded by the SPINNER PhD grant scheme (Reg ione Emilia Romagna) together with extramural funds by Giovanni Gabbianelli (University of Bologna). RFO (to R.B) and the Marco Polo travel grant (to V.F.) are acknowledged. Gianluca Bianchini and Renzo Tassinari are thanked for the ICP MS analyses at the University of Ferrara. Montanuniversität Leoben is thanked for the support in the analytical work. We would like to acknowledge three anonymous reviewers for their useful comments and especially the editor for the handling of this paper.

\section{Appendix A. Supplementary material}

Supplementary data associated with this article can be found, in the online version, at http://dx.doi.org/10.1016/j.wasman.2014. 11.005 .

\section{References}

Allegrini, E., Maresca, A., Olsson, M.E., Holtze, M.S., Boldrin, A., Astrup, T.F., 2014. Quantification of the resource recovery potential of municipal solid waste incineration bottom ashes. Waste Manage. 34 (9), 1627-1636. http://dx.doi.org/ 10.1016/j.wasman.2014.05.003.

Astrup, T., Riber, C., Pedersen, A.J., 2011. Incinerator performance: effects of changes in waste input and furnace operation on air emissions and residues. Waste Manage. Res. 29 (10 Suppl), 57-68. http://dx.doi.org/10.1177/ 0734242 X11419893.

Astrup, T.F., Tonini, D., Turconi, R., Boldrin, A., 2015. Life cycle assessment of thermal waste-to-energy technologies: review and recommendations. Waste Manage.

37, 104-115.

Bayuseno, A.P., Schmahl, W.W., 2010. Understanding the chemical and mineralogical properties of the inorganic portion of MSWI bottom ash. Waste Manage. 30 (8-9), 1509-1520. http://dx.doi.org/10.1016/j.wasman.2010. 03.010 .

Belevi, H., Moench, H., 2000. Factors determining the element behaviour in municipal solid waste incinerators 1. - Field studies. Environ. Sci. Technol. 34, 2501-2506.

Bertolini, L., Carsana, M., Cassago, D., Quadrio Curzio, A., Collepardi, M., 2004. MSWI ashes as mineral additions in concrete. Cem. Concr. Res. 34 (10), 1899-1906. http://dx.doi.org/10.1016/j.cemconres.2004.02.001.

Brunner, P.H., Ernst, W.R., 1986. Alternative methods for the analysis of municipal solid waste. Waste Manage. Res. 4 (2), 147-160, <http://dx.doi.org/>. 
Brunner, P.H., Mönch, H., 1986. The flux of metals through municipal solid waste incinerators. Waste Manage. Res. 4 (1), 105-119, <http://dx.doi.org/>.

Brunner, P.H., Rechberger, H., 2004. Methodology of MFA. In: Practical Handbook of Material Flow Analysis. Lewis Publishers $\odot$, Boca Raton London New York Washington, D.C., pp. 34-166, ISBN: 1-5667-0604-1.

Chandler, A.J., Eighmy, T.T., Hartlén, J., Hjelmar, O., Kosson, D.S., Sawell, S.E., van der Sloot, H.A., Vehlow, J. 1997. Municipal solid waste incinator residues, Studies in Environmental Science, 67, Elsevier SCIENCE B.V., The Netherlands, pp. 1009 ISBN: 0-44482563-0.

Chung, Y.-S., Moon, J.-H., Kim, S.-H., Kang, S.-H., Kim, Y.-J., 2007. Determination of the elemental composition of the bottom ash of a municipal incinerator by instrumental neutron activation analysis. J. Radioanal. Nucl. Chem. 271 (2), 339-344.

Cornelis, G., Johnson, C.A., Gerven, T.V., Vandecasteele, C., 2008. Leaching mechanisms of oxyanionic metalloid and metal species in alkaline solid wastes: a review. Appl. Geochem. 23 (5), 955-976. http://dx.doi.org/10.1016/ j.apgeochem.2008.02.001.

De Boom, A., Degrez, M., 2012. Belgian MSWI fly ashes and APC residues: a characterisation study. Waste Manage. 32 (6), 1163-1170. http://dx.doi.org/ 10.1016/j.wasman.2011.12.017.

European Commission, 2008. Directive 2008/98/EC of the European parliament and of the council of 19 November 2008 on waste and repealing certain directives. Official J. Eur. Union L312, 3-30.

European Commission, 2010. Critical Raw Materials for EU - Report of the Ad-hoc Working Group on defining Critical Raw Materials. <http://ec.europa.eu/ enterprise/policies/raw materials/critical/>. European Commission.

European Commission, 2014. Critical Raw Materials for EU - Report of the Ad-hoc Working Group on defining Critical Raw Materials - May 2014 update. <http:// ec.europa.eu/enterprise/policies/raw materials/critical/>. European Commission.

Fujimori, E., Minamoto, K., Iwata, S., Chiba, K., Haraguchi, H., 2004. Enrichment of elements in industrial waste incineration bottom ashes obtained from three different types of incinerators, as studied by ICP-AES and ICP-MS. J. Mater. Cycles Waste Manage. 6 (1), 73-79. http://dx.doi.org/10.1007/s10163-003-0106-6.

Geologic Survey of Finland - GTK website (http://en.gtk.fi/). Report: "Metal mines active in 2013 in Fennoscandia". Pdf-format document viewed on the 27th October 2014 at the: <http://en.gtk.fi/export/sites/en/informationservices/ databases/fodd/large_active_mines.pdf $>$.

Hasegawa, H., Rahman, I.M.M., Egawa, Y., Sawai, H., Begum, Z.A., Maki, T., Mizutani, S., 2014. Recovery of the rare metals from various waste ashes with the aid of temperature and ultrasound irradiation using chelants. Water, Air, Soil Pollut. 225 (9). http://dx.doi.org/10.1007/s11270-014-2112-9.

Hu, Y., Zhang, P., Chen, D., Zhou, B., Li, J., Li, X.-W., 2012. Hydrothermal treatment of municipal solid waste incineration fly ash for dioxin decomposition. J. Hazard. Mater. 207-208, 79-85. http://dx.doi.org/10.1016/j.jhazmat.2011.05.068.

Hyks, J., Astrup, T., Christensen, T.H., 2009. Leaching from MSWI bottom ash: evaluation of non-equilibrium in column percolation experiments. Waste Manage. 29 (2), 522-529. http://dx.doi.org/10.1016/j.wasman.2008.06.011.

ISPRA, 2013. Rapporto Rifiuti Urbani: Edizione 2013. ISPRA - Istituto Superiore per la Protezione e la Ricerca Ambientale - Report, 176/2013. ISBN:

978-88-448-0596-8.

Izquierdo, M., Vazquez, E., Querol, X., Barra, M., Lòpez, A., Plana, F., 2001. Use of bottom ash from municipal solid waste incineration as a road material. Paper presented at the International Ash Utilization Symposium, Center for Applied Energy Research, University of Kentucky. <http://www.flyash.info>.

Jiang, S.-H., Han, F., Shen, J.-Z., Palmer, M.R., 1999. Chemical and Rb-Sr, Sm-Nd isotopic systematics of tormaline from the Dachang Sn-polymetallic ore deposit, Guangxi Province, PR China. Chem. Geol. 157, 49-67.

Jung, C.H., Osako, M., 2007. Thermodynamic behavior of rare metals in the melting process of municipal solid waste (MSW) incineration residues. Chemosphere 69 (2), 279-288. http://dx.doi.org/10.1016/j.chemosphere.2007.03.071.

Jung, C.H., Osako, M., 2009. Leaching characteristics of rare metal elements and chlorine in fly ash from ash melting plants for metal recovery. Waste Manage. 29 (5), 1532-1540. http://dx.doi.org/10.1016/j.wasman.2008.08.014.

Kaur, A., Patil, G.P., Shirk, S.J., Taillie, C., 1996. Environmental sampling with a concomitant variable: a comparison between ranked set sampling and stratified simple random sampling. J. Appl. Stat. 23 (2-3), 231-256. http://dx.doi.org/ $10.1080 / 02664769624224$

Kida, A., Noma, Y., Imada, T., 1996. Chemical speciation and leaching properties of elements in municipal incinerator ashes. Waste Manage. 16, 527-536.

Li, H., Watanabe, K., Xi, X.-S., Yonezu, K., 2013. Geochemistry of volcanic rocks at zhaokalong iron-copper-polymetallic ore deposit, qinghai province, china: implications for the tectonic background. Proc. Earth Planet. Sci. 6, 58-63. http://dx.doi.org/10.1016/j.proeps.2013.01.008.

Li, M., Xiang, J., Hu, S., Sun, L.-S., Su, S., Li, P.-S., Sun, X.-X., 2004. Characterization of solid residues from municipal solid waste incinerator. Fuel 83 (10), 1397-1405. http://dx.doi.org/10.1016/j.fuel.2004.01.005.

Meima, J.A., Comans, R.N.J., 1999. The leaching of trace elements from municipal solid waste incinerator bottom ash at different stages of weathering. Appl. Geochem. 14, 159-171, doi: 0883-2927/99/\$.

Meisel, T., Schoner, N., Paliulionyte, V., Kahr, E., 2002. Determination of rare earth elements, $\mathrm{Y}, \mathrm{Th}, \mathrm{Zr}, \mathrm{Hf}, \mathrm{Nb}$ and $\mathrm{Ta}$ in geological reference materials G-2, G-3, Sco- 1 and WGB-1 by sodium peroxide sintering and inductively coupled plasma-mass spectrometry. Geostandard Newslett 26, 53-61.

Mohapatra, B.K., Mishra, P.P., Singh, P.P., Rajeev, 2009. Manganese ore deposits in Koira-Noamundi province of Iron Ore Group, north Orissa, India: in the light of geochemical signature. Chem. Erde-Geochem. 69 (4), 377-394. http:// dx.doi.org/10.1016/j.chemer.2009.06.001.

Morf, L.S., Gloor, R., Haag, O., Haupt, M., Skutan, S., Di Lorenzo, F., Boni, D., 2013. Precious metals and rare earth elements in municipal solid waste - sources and fate in a Swiss incineration plant. Waste Manage. 33 (3), 634-644. http:// dx.doi.org/10.1016/j.wasman.2012.09.010

Muchova, L., Bakker, E., Rem, P., 2009. Precious metals in municipal solid waste incineration bottom ash. Water, Air, Soil Pollut.: Focus 9 (1-2), 107-116. http:// dx.doi.org/10.1007/s11267-008-9191-9.

Pan, Y., Wu, Z., Zhou, J., Zhao, J., Ruan, X., Liu, J., Qian, G., 2013. Chemical characteristics and risk assessment of typical municipal solid waste incineration (MSWI) fly ash in China. J. Hazard. Mater. 261, 269-276. http:// dx.doi.org/10.1016/j.jhazmat.2013.07.038.

Rudnick, R.L., Gao, S., 2014, . Composition of the Continental Crust. From: Treatise on Geochemistry, second ed., vol. 4. Elsevier Inc. Turekian, K. K., \& Holland, H. D., pp. 1-51. doi: http://dx.doi.org/10.1016/b978-0-08-095975-7.00301-6.

Santos, R.M., Mertens, G., Salman, M., Cizer, O., Van Gerven, T., 2013. Comparative study of ageing, heat treatment and accelerated carbonation for stabilization of municipal solid waste incineration bottom ash in view of reducing regulated heavy metal/metalloid leaching. J. Environ. Manage. 128, 807-821. http:/l dx.doi.org/10.1016/j.jenvman.2013.06.033.

Sekito, T., Dote, Y., Onoue, K., Sakanakura, H., Nakamura, K., 2014. Characteristics of element distributions in an MSW ash melting treatment system. Waste Manag

34 (9), 1637-1643. http://dx.doi.org/10.1016/j.wasman.2014.04.009.

UNI EN 10802, 2013. Waste - manual sampling, sample preparation and analysis of eluates. UNI - Ente nazionale italiano di unificazione (Italian unification authority). Standard Number: UNI 10802:2013; Start Validity Date: august 6, 2013.

Wan, X., Wang, W., Ye, T., Guo, Y., Gao, X., 2006. A study on the chemical and mineralogical characterization of MSWI fly ash using a sequential extraction procedure. J. Hazard. Mater. 134 (1-3), 197-201. http://dx.doi.org/10.1016/ j.jhazmat.2005.10.048.

Yao, J., Kong, Q., Zhu, H., Long, Y., Shen, D., 2013. Content and fractionation of Cu, Zn and $\mathrm{Cd}$ in size fractionated municipal solid waste incineration bottom ash. Ecotoxicol. Environ. Saf. 94, 131-137. http://dx.doi.org/10.1016/j.ecoenv.2013. 05.014

Zhang, H., He, P.J., Shao, L.M., 2008a. Fate of heavy metals during municipal solid waste incineration in Shanghai. J. Hazard. Mater. 156 (1-3), 365-373. http:// dx.doi.org/10.1016/j.jhazmat.2007.12.025.

Zhang, Y., Jiang, J., Chen, M., 2008b. MINTEQ modeling for evaluating the leaching behavior of heavy metals in MSWI fly ash. J. Environ. Sci. 20, 1398-1402.

Zhao, L., Zhang, F.S., Zhang, J., 2008. Chemical properties of rare earth elements in typical medical waste incinerator ashes in China. J. Hazard. Mater. 158 (2-3) 465-470. http://dx.doi.org/10.1016/j.jhazmat.2008.01.091. 